\title{
Effects of TACE combined with precise RT on p53 gene expression and prognosis of $\mathrm{HCC}$ patients
}

\author{
YUPENG LIU ${ }^{1 *}$, JINGCHEN YAN $^{2 *}$ and FENG WANG ${ }^{3}$ \\ ${ }^{1}$ Department of Emergency, The First People's Hospital of Qinhuangdao, The Affiliated Hospital of Hebei Medical University, \\ Qinhuangdao, Hebei 066000; ${ }^{2}$ Department of Intervention, Liaocheng Cancer Hospital, Liaocheng, Shandong 252000; \\ ${ }^{3}$ Department of Nuclear Medicine, The First Hospital of Shijiazhuang, Shijiazhuang, Hebei 050011, P.R. China
}

Received January 12, 2018; Accepted July 30, 2018

DOI: $10.3892 / \mathrm{ol} .2018 .9374$

\begin{abstract}
To investigate the effects of transcatheter arterial chemoembolization (TACE) combined with precise radiation therapy (RT) on p53 gene expression and prognosis of patients with hepatocellular carcinoma (HCC). A total of 80 patients with unresectable HCC treated in the First People's Hospital of Qinhuangdao from March 2009 to March 2015 were randomly divided into TACE group $(n=40)$ and TACE + RT group $(n=40)$. Enzyme-linked immunosorbent assay (ELISA) was used to detect the levels of p53 in both groups before and after treatment. The biochemical indexes of liver function $[\alpha$-fetoprotein (AFP), alanine aminotransferase (ALT) and $\gamma$-glutamyl transferase(GGT)] were detected.Moreover, adverse reactions were compared between the two groups of patients, the short-term therapeutic effect was evaluated, and effects of two treatment methods on progression-free survival (PFS) and overall survival (OS) of patients were detected. There were no statistically significant differences in clinical data between the two groups of patients $(\mathrm{P}>0.05)$. The p53 protein levels were significantly downregulated in both treatment methods, and it was decreased more significantly in TACE + RT group than that in TACE group $(\mathrm{P}<0.05)$. Compared with those before treatment, AFP and GGT levels in both groups of patients after treatment were decreased, but the levels of ALT were increased $(\mathrm{P}<0.05)$, and TACE + RT group had a better curative effect than TACE group $(\mathrm{P}<0.05)$. Besides, the incidence rate of adverse reactions in TACE + RT group (37.5\%) was obviously lower than that in TACE group $(65 \%)(\mathrm{P}<0.05)$. The number of patients with stable disease (SD) and progressive disease (PD) and disease control rate (DCR) in TACE + RT
\end{abstract}

Correspondence to: Dr Feng Wang, Department of Nuclear Medicine, The First Hospital of Shijiazhuang, 36 van West Road, Shijiazhuang, Hebei 050011, P.R. China

E-mail: bengchan17@163.com

*Contributed equally

Key words: transcatheter arterial chemoembolization, radiation therapy, hepatocellular carcinoma, p53 group were superior to those in TACE group $(\mathrm{P}<0.05)$. The 2-year survival rate and median PFS of patients in TACE + RT group were also significantly better than those in TACE group $(\mathrm{P}<0.05)$. In conclusion, TACE combined with RT has a better clinical effect than TACE alone in the treatment of HCC.

\section{Introduction}

Hepatocellular carcinoma (HCC) is one of the most common malignant tumors in Asian countries, and surgical resection may be the only treatment means (1-3). However, only $>20 \%$ patients are eligible for surgical treatment (4). Even for patients who are able to receive surgical treatment, HCC will eventually relapse in approximately $30-60 \%$ of them (5). Non-surgical treatment means include transcatheter arterial chemoembolization (TACE), percutaneous acetic acid and ethanol injection therapy and precise radiation therapy (RT). Several authoritative agencies have reported that patients with unresectable HCC can benefit a lot from receiving partial liver RT $(6,7)$, especially those with portal venous thrombosis or invasive liver tumor $(8,9)$. With the development of three-dimensional conformal intensitymodulated RT technique, namely the precise RT, partial liver RT has become safer. Although the effect of RT at the radiation site is significant, $\mathrm{HCC}$ frequently relapses in other intrahepatic sites or develops into extrahepatic metastasis in patients treated with RT alone (10). Human p53 gene, located on the short arm of chromosome 17, encodes a $53 \mathrm{kDa}$ nuclear phosphoprotein, which is an important negative regulator of cell growth $(11,12)$. The wild-type p53, as a product of tumor suppressor gene protein, regulates the cell cycle. Besides, wild-type p53 has a shorter half-life (20 min), so it is difficult to detect p53 protein in normal tissues. However, p53 gene mutation is often detected in a variety of human tumor tissues, and the half-life of products after p53 gene mutation is prolonged and the function of regulating cell cycle is lost, thus making cell growth out of control (13). However, the correlations of TACE and RT with serum p53 level and therapeutic effect on HCC have not been clearly reported.

In this experiment, HCC patients were treated with TACE combined with RT and TACE alone, so as to investigate whether the two methods can increase the serum p53 level in 
patients and comprehensively evaluate the clinical effects of the two treatment methods.

\section{Materials and methods}

Clinical data. A total of 80 patients with unresectable HCC treated in the Emergency Treatment of the First People's Hospital of Qinhuangdao (Qinhuangdao, China) from March 2009 to March 2015 were selected. Inclusion criteria were determined by surgeons based on the currently-accepted surgical criteria. Seventy-two cases were histologically confirmed as HCC, while the remaining 8 cases were not confirmed histologically due to the refusal of biopsy, but the imaging examination and biochemical test results were consistent with HCC. None of patients enrolled received any anticancer therapy before operation. Patients were aged 36-78 years old with an average age of 58.4 4.9 years old, and general clinicopathological data had no statistically significant differences. All patients signed the informed consent, and this clinical test was approved by the Ethics Committee of the First People's Hospital of Qinhuangdao.

Grouping and treatment methods. In this study, $80 \mathrm{HCC}$ patients were randomly divided into TACE group $(n=40)$ and TACE + RT group $(n=40)$. TACE treatment: The catheter was inserted into the hepatic artery via femoral artery using Seldinger technique, followed by hepatic arteriography. After the correct positioning of catheter, 30-50 mg doxorubicin and $20 \mathrm{mg}$ hydroxycamptothecine were used as chemotherapy drugs. Thirty milliliters ultra-fluid lipiodol embolic agent and gelatin sponge particles were used for embolization. The treatment was performed for 3 times (1 time/month). TACE + RT: Patients underwent RT after TACE treatment for 3 times. After oral administration of contrast agent, the radiation area was accurately determined under the guidance of spiral computed tomography (CT). Be careful to avoid the entire liver from being in the radiation area. Gross target volume (GTV) was drawn under the assistance of computer. The outward expansion for $1 \mathrm{~cm}$ based on GTV indicated the clinical target volume (CTV). According to the location and size of tumor, the outward expansion for $1.5-2 \mathrm{~cm}$ based on CTV indicated the planning target volume (PTV). The average tumor dose was 44 Gy. During treatment, the liver function of patients was examined once a week.

Detection of p53 and biochemical indexes. The blood was drawn from all patients before and after treatment, let stand at room temperature for $1 \mathrm{~h}$, and stratified. The upper-layer serum was taken to detect the serum p53 protein level using the enzyme-linked immunosorbent assay (ELISA) kit (cat. no. ab171571; Abcam, Cambridge, NY, USA) according to instructions. The levels of biochemical indexes of liver function $[\alpha$-fetoprotein (AFP), alanine aminotransferase (ALT) and $\gamma$-glutamyl transferase (GGT)] were determined by the Laboratory Department of our hospital.

Therapeutic effect evaluation and follow-up. According to the modified response evaluation criteria in solid tumors (mRECIST) (14), tumor response was evaluated at 3 months after treatment based on the observation of changes in
Table I. Comparisons of general clinicopathologic data between the two groups of patients.

\begin{tabular}{lc}
\hline Clinicopathologic \\
\cline { 2 - 2 } data
\end{tabular}

\begin{tabular}{lllll}
\hline $\begin{array}{l}\text { Age (years) } \\
\leq 60\end{array}$ & 46 & 19 & 17 & 0.643 \\
$>60$ & 34 & 21 & 13 & \\
Sex & & & & \\
$\quad$ Male & 47 & 18 & 29 & 0.529 \\
Female & 33 & 12 & 11 & \\
Serum albumin & & & & \\
$\leq 35$ g/l & 44 & 20 & 22 & 0.392 \\
$>35$ g/l & 36 & 20 & 16 &
\end{tabular}

Liver function

classification

$\begin{array}{lllll}\text { Child-Pugh A } & 37 & 21 & 16 & 0.301 \\ \text { Child-Pugh B } & 43 & 19 & 24 & \\ \text { Cirrhosis } & & & & \\ \text { No } & 41 & 16 & 25 & 0.105 \\ \text { Yes } & 39 & 24 & 15 & \end{array}$

Tumor size $(\mathrm{cm})$

$\begin{array}{lllll}\leq 5 & 49 & 25 & 24 & 0.736 \\ >5 & 31 & 15 & 16 & \end{array}$

Tumor capsule

$\begin{array}{lllll}\text { No } & 42 & 27 & 25 & 0.250 \\ \text { Yes } & 38 & 13 & 25 & \\ \text { No. of tumors (cm) } & & & & \\ \text { Single } & 49 & 27 & 22 & 0.738 \\ \text { Multiple } & 31 & 13 & 18 & \end{array}$

Edmondson-Steiner

grading

$\begin{array}{lllll}\text { I-II } & 50 & 30 & 20 & 0.087 \\ \text { III-IV } & 30 & 10 & 20 & \\ \text { Vascular invasion } & & & & \\ \text { No } & 37 & 25 & 12 & 0.092 \\ \text { Yes } & 43 & 15 & 28 & \end{array}$

TACE, transcatheter arterial chemoembolization; RT, radiation therapy.

tumor size via dynamic CT scan: Complete remission (CR), complete disappearance of tumors; partial remission (PR), decrease of tumor size to $50 \%$ of the initial volume; stable disease (SD), decrease of tumor size to $<30 \%$ of the initial volume or no change and progressive disease (PD). The response rate of $\mathrm{CR}, \mathrm{PR}, \mathrm{SD}$ or $\mathrm{PD}$ was calculated. The overall response rate $(\mathrm{RR})=\mathrm{CR}+\mathrm{PR}$, and the disease control rate $(\mathrm{DCR})=\mathrm{CR}+\mathrm{PR}+\mathrm{SD}$. Patients were followed up via outpatient or telephone after treatment for 18 months. In this experiment, 6 cases were lost to follow-up, and the remaining 74 cases were in the study cohort. 
Table II. Changes in AFP, ALT and GGT levels in both groups of patients before and after treatment $(\mathrm{mean} \pm \mathrm{SD})$.

\begin{tabular}{|c|c|c|c|c|c|c|}
\hline \multirow[b]{2}{*}{ Groups } & \multicolumn{2}{|c|}{$\mathrm{AFP}(\mu \mathrm{g} / \mathrm{l})$} & \multicolumn{2}{|c|}{$\operatorname{ALT}(\mathrm{U} / \mathrm{l})$} & \multicolumn{2}{|c|}{ GGT (U/1) } \\
\hline & Before treatment & After treatment & Before treatment & After treatment & Before treatment & After treatment \\
\hline TACE & $513.76 \pm 78.22$ & $367.36 \pm 98.90^{\mathrm{b}, \mathrm{d}}$ & $51.63 \pm 10.73$ & $124.23 \pm 85.26^{\mathrm{b}, \mathrm{c}}$ & $410.56 \pm 76.30$ & $243.51 \pm 83.23^{\mathrm{b}, \mathrm{c}}$ \\
\hline $\mathrm{TACE}+\mathrm{RT}$ & $553.81 \pm 92.73$ & $201.82 \pm 84.77^{b}$ & $48.93 \pm 13.62$ & $176.17 \pm 79.43^{b}$ & $394.73 \pm 92.84$ & $158.83 \pm 93.47^{\mathrm{a}}$ \\
\hline
\end{tabular}

Compared with that before treatment: ${ }^{\mathrm{a}} \mathrm{P}<0.05$ and ${ }^{\mathrm{b}} \mathrm{P}<0.01$. Compared with that in TACE group: ${ }^{\mathrm{c}} \mathrm{P}<0.05$ and ${ }^{\mathrm{d}} \mathrm{P}<0.01$. AFP, $\alpha$-fetoprotein; ALT, alanine aminotransferase; GGT, $\gamma$-glutamyl transferase.

Table III. Adverse reactions in both groups of patients.

\begin{tabular}{|c|c|c|c|c|c|c|c|c|c|}
\hline Groups & No. & Infection & $\begin{array}{l}\text { Hepatic } \\
\text { failure }\end{array}$ & Leucopenia & Diarrhea & Hematemesis & $\begin{array}{l}\text { Headache } \\
\text { and vertigo }\end{array}$ & $\begin{array}{c}\text { Elevated blood } \\
\text { pressure }\end{array}$ & $\begin{array}{c}\text { Incidence rate } \\
\text { of adverse } \\
\text { reactions }(\%)\end{array}$ \\
\hline TACE & 40 & 1 & 3 & 2 & 6 & 1 & 10 & 3 & $65(26 / 40)$ \\
\hline $\mathrm{TACE}+\mathrm{RT}$ & 40 & 0 & 1 & 1 & 4 & 0 & 8 & 1 & $37.5(15 / 40)$ \\
\hline$c^{2}$ & & & & & & & & & 1.252 \\
\hline P-value & & & & & & & & & 0.047 \\
\hline
\end{tabular}

TACE, transcatheter arterial chemoembolization; RT, radiation therapy.

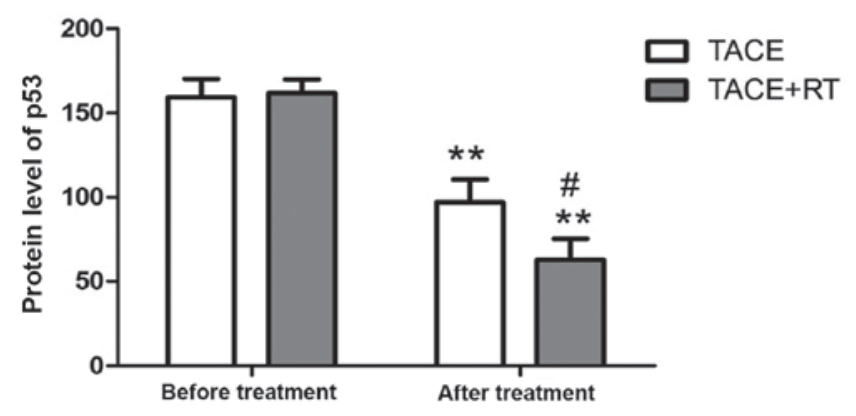

Figure 1. p53 levels in both groups before and after treatment. Compared with that before treatment, ${ }^{* *} \mathrm{P}<0.01$. Compared with that in TACE group, ${ }^{*} \mathrm{P}<0.05$.

Statistical methods. GraphPad Prism statistical software (version 5.01; GraphPad Software, Santiago, Chile) was used for analysis. Chi-square test was used for the correlations of general clinicopathologic data between the two groups of patients. The progression-free survival (PFS) and overall survival (OS) curves of the two groups of patients were drawn using Kaplan-Meier method, and the survival differences between the two groups were compared by log-rank test. Measurement data were presented as (mean \pm SD), and independent-samples t-test was used to compare the difference in $\mathrm{p} 53$ expression between the two groups. $\mathrm{P}<0.05$ suggested that the difference was statistically significant.

\section{Results}

Comparisons of general clinicopathologic data between the two groups of patients. There were no statistically significant differences in age, sex, serum albumin, liver function classification, cirrhosis, tumor size, tumor capsule, number of tumors, Edmondson-Steiner grading and vascular invasion in patients between TACE + RT group and TACE group $(\mathrm{P}>0.05)$ (Table I), and follow-up experiments could be performed.

p53 expression level. There was no statistically significant difference in the p53 protein level between the two groups of patients before treatment $(\mathrm{P}>0.05)$. After treatment, the levels of p53 protein in both groups were decreased compared with those before treatment $(\mathrm{P}<0.05)$, and it was lower in TACE + RT group than that in TACE group $(\mathrm{P}<0.05)($ Fig. 1).

Changes in relevant biochemical indexes in both groups of patients before and after treatment. AFP, ALT and GGT levels had no statistically significant differences in both groups of patients before treatment $(\mathrm{P}<0.05)$. After treatment, AFP and GGT levels in both groups of patients were decreased compared with those before treatment, but ALT levels were increased compared with those before treatment $(\mathrm{P}<0.05)$. TACE + RT group had a better curative effect than TACE group $(\mathrm{P}<0.05)$ (Table II).

Adverse reactions in both groups of patients. After patients received TACE and/or RT, common adverse reactions include infection, hepatic failure, leucopenia, diarrhea, nausea, hematemesis, and elevated blood pressure. In this experiment (Table III), there was 1 case of infection, 3 cases of hepatic failure, 2 cases of leucopenia, 6 cases of diarrhea, 1 case of hematemesis, 10 cases of headache and vertigo, and 3 cases of elevated blood pressure in TACE group, and the 
Table IV. Response rates to different treatment methods in both groups of HCC patients.

\begin{tabular}{lccc}
\hline Items & $\begin{array}{c}\text { TACE } \\
(\mathrm{n}=40) \mathrm{n}(\%)\end{array}$ & $\begin{array}{c}\text { TACE }+\mathrm{RT} \\
(\mathrm{n}=40) \mathrm{n}(\%)\end{array}$ & P-value \\
\hline CR & $0(0)$ & $0(0)$ & - \\
PR & $4(10)$ & $6(15)$ & - \\
SD & $16(40)$ & $23(57.5)$ & 0.047 \\
PD & $26(65)$ & $17(42.5)$ & 0.041 \\
RR & $4(10)$ & $6(15)$ & - \\
DCR & $20(50)$ & $29(72.5)$ & 0.032 \\
\hline
\end{tabular}

HCC, hepatocellular carcinoma; TACE, transcatheter arterial chemoembolization; RT, radiation therapy; $\mathrm{CR}$, complete remission; $\mathrm{PR}$, partial remission; $\mathrm{SD}$, stable disease; $\mathrm{PD}$, progressive disease; $\mathrm{RR}$, response rate; DCR, disease control rate.

Table V. Comparison of survival time between both groups of patients.

\begin{tabular}{lccc}
\hline Groups & $\begin{array}{c}\text { 2-year survival } \\
\text { rate }(\%)\end{array}$ & $\begin{array}{c}\text { Median PFS } \\
\text { (months) }\end{array}$ & $\begin{array}{c}\text { Median OS } \\
\text { (months) }\end{array}$ \\
\hline TACE & 22.7 & 6.45 & 9 \\
TACE + RT & 37.4 & 10.54 & 13.4 \\
c $^{2}$ & 3.321 & 5.341 & 4.825 \\
P-value & 0.043 & 0.0261 & 0.0350 \\
\hline
\end{tabular}

TACE, transcatheter arterial chemoembolization; RT, radiation therapy; PFS, progression-free survival; OS, overall survival.

incidence rate of adverse reactions was $65 \%$. In TACE + RT group, there was 1 case of hepatic failure, 1 case of leucopenia, 4 cases of diarrhea, 8 cases of headache and vertigo and 1 case of elevated blood pressure, and the incidence rate of adverse reactions was $37.5 \%$, which was significantly lower than that in TACE group $(\mathrm{P}<0.05)$.

Comparisons of short-term treatment effects between both groups of patients. SD and DCR of patients in TACE + RT group were obviously higher than those in TACE group, but $\mathrm{PD}$ was lower than that in TACE group $(\mathrm{P}<0.05)$ (Table IV).

Comparison of survival time. In TACE group, the 2-year survival rate of patients was $22.7 \%$, the median PFS was 6.45 months, and the median OS was 9 months. In TACE + RT group, the 2-year survival rate was $37.4 \%$, the median PFS was 10.54 months, and the median OS was 13.4 months. The results showed that patients in TACE + RT group had longer survival time than those in TACE group $(\mathrm{P}<0.05)$ (Table V and Fig. 2).

\section{Discussion}

TACE is one of the main treatment methods for HCC, especially unresectable and advanced HCC. TACE exerts an anticancer effect by selectively blocking the arterial blood supply of HCC. TACE can be used for multiple intrahepatic
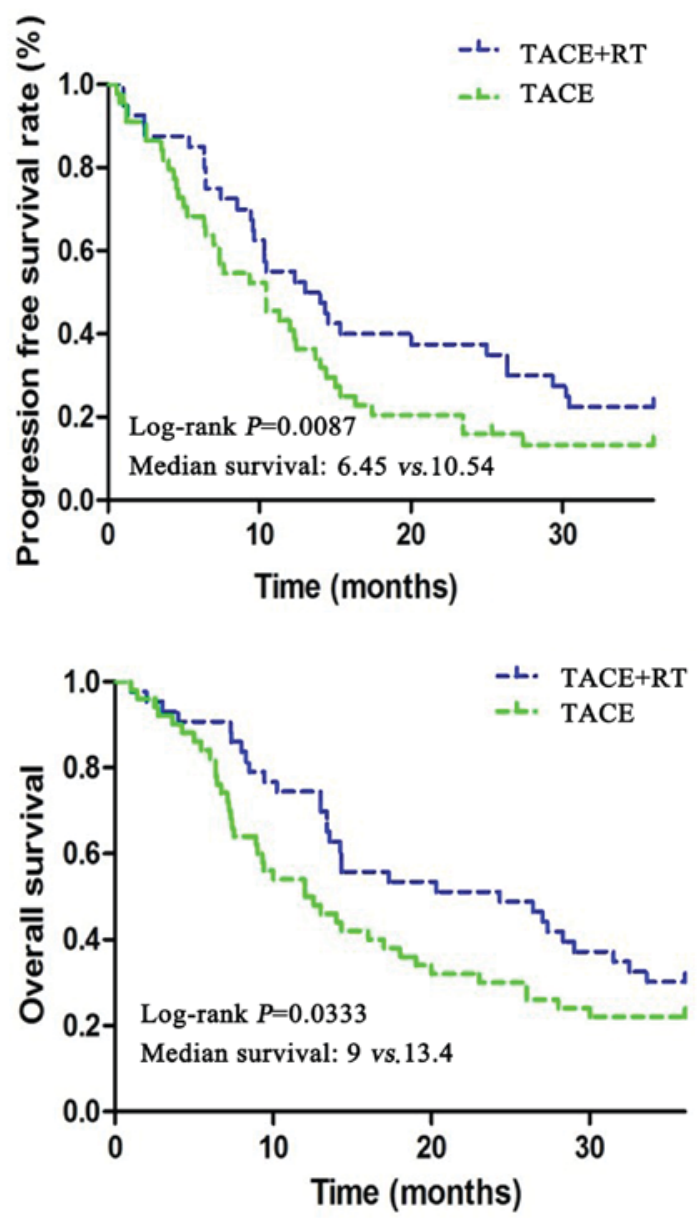

Figure 2. Progression-free survival (PFS) and overall survival (OS) of patients in both groups.

tumors. However, due to complex blood supply, it is less effective in the control of larger tumors (15). The blood supply of small tumors is usually in the hepatic artery only, and the blood supply in extrahepatic artery is increased in large tumors. RT can be used as a complement to TACE for large tumors (16). Due to the limitations of radiotherapy techniques in the past, HCC was mistakenly considered as an RT-insensitive tumor (17). With the development of precision medicine and modern radiotherapy techniques (such as three-dimensional conformal radiotherapy and intensity-modulated radiotherapy) at present, tumors can be treated at higher doses, and normal tissues around the tumor can be better protected. Now, RT is a safe and effective treatment means for primary $\mathrm{HCC}$, and its role is gradually being taken seriously (18).

Matsuura et al reported 22 cases of simple RT or TACE + ethanol injection therapy (19). In the study of Seong et al, 30 cases received TACE treatment at 7-10 days after local RT (20). Im et al treated HCC patients with RT twice a day, as well as hepatic arterial infusion of fluorodeoxyuridine (9). Jung and Shin treated 3-8 cm HCC with TACE, ethanol injection and RT (21). These experiments show that TACE combined with RT has a better curative effect than TACE or RT alone.

Functional inactivation of p53 is related to many different mechanisms, including: i) p53 forms stable non-functional complexes with viral proteins, ii) p53 binds to intracellular proteins, such as heat shock protein 70 , leading to loss of normal 
function of p53, and iii) p53 mutation: p53 mutations are found in 60-65\% human tumors, and this is also a major cause of p53 functional inactivation (22). Types of p53 gene mutations include point mutation, deletion mutation, frameshift mutation and gene rearrangement. Mutation sites are more concentrated in the first 5-8 exons. Abnormal protein is produced and accumulates in cancer cells. Its half-life is also increased from 15-20 min to a few hours. At present, it has been reported that the injection of p53 gene with overexpression of p53 virus can replace the mutated p53 site, thus promoting p53 to play a role in inhibiting tumor growth (23).

According to our data, TACE combined with RT offers greater benefit to tumor patients than TACE alone. PFS and OS of patients in TACE + RT group were longer than those in TACE group, and the 2-year survival rate in TACE + RT group was up to $37.4 \%$, which was higher than that in TACE group. Importantly, p53 in serum of patients in TACE + RT group was significantly decreased, compared with that in TACE group. It is reported in the literature that DNA damage in tumor cells is induced after gamma-ray irradiation, thereby increasing the level of p53 protein phosphorylation (24). In addition, studies have shown that the wild-type p53 expression is increased after RT for more than $96 \mathrm{~h}$ (25), which may be an important reason for the improved prognosis of patients. The specific mechanism remains to be further proved via experiments. In this experiment, in addition to higher ALT and GGT levels after treatment, AFP in patients in TACE group also remained at a relatively high level. AFP is a factor of poor prognosis of HCC patients, which may be one of the reasons for poorer prognosis of patients in TACE group than that in TACE + RT group.

In conclusion, this study showed that the treatment of patients who cannot receive surgical treatment with simple TACE leads to poor survival, serious disease and short survival time. However, TACE combined with RT can significantly increase the survival time and improve the prognosis of patients.

\section{Acknowledgements}

Not applicable.

\section{Funding}

No funding was received.

\section{Availability of data and materials}

The datasets used and/or analyzed during the current study are available from the corresponding author on reasonable request.

\section{Authors' contributions}

FW designed the study, YL conducted the experiments and JY collected and analyzed the data. YL and FW wrote and approved the manuscript. All authors read and approved the final manuscript.

\section{Ethics approval and consent to participate}

The study was approved by the Ethics Committee of the First People's Hospital of Qinhuangdao (Qinhuangdao, China).
Written informed consents were signed by the patients and/ or guardians.

\section{Patient consent for publication}

Not applicable.

\section{Competing interests}

The authors declare that they have no competing interests.

\section{References}

1. Halliday J, Helmy K, Pattwell SS, Pitter KL, LaPlant Q, Ozawa T and Holland EC: In vivo radiation response of proneural glioma characterized by protective 553 transcriptional program and proneural-mesenchymal shift. Proc Natl Acad Sci USA 111: 5248-5253, 2014

2. Oishi N, Yamashita T and Kaneko S: Molecular biology of liver cancer stem cells. Liver Cancer 3: 71-84, 2014.

3. Ryerson AB, Eheman CR, Altekruse SF, Ward JW, Jemal A, Sherman RL, Henley SJ, Holtzman D, Lake A, Noone AM, et al: Annual Report to the Nation on the Status of Cancer, 1975-2012, featuring the increasing incidence of liver cancer. Cancer 122: 1312-1337, 2016.

4. Siegel RL, Miller KD and Jemal A: Cancer statistics, 2016. CA Cancer J Clin 66: 7-30, 2016.

5. Zhang Y, Liu S, Wang X, Zhang Z, Jing X, Zhang P and Xie Z: Prevention of local liver cancer recurrence after surgery using multilayered cisplatin-loaded polylactide electrospun nanofibers. Chin J Polym Sci 8: 1111-1118, 2014.

6. Bruix J, Han KH, Gores G, Llovet JM and Mazzaferro V: Liver cancer: Approaching a personalized care. J Hepatol 62 (Suppl 1): S144-S156, 2015.

7. Fiore F, Del Prete M, Franco R, Marotta V, Ramundo V, Marciello F, Di Sarno A, Carratù AC, de Luca di Roseto C, Colao A, et al: Transarterial embolization (TAE) is equally effective and slightly safer than transarterial chemoembolization (TACE) to manage liver metastases in neuroendocrine tumors. Endocrine 47: 177-182, 2014.

8. Lee DS and Seong J: Radiotherapeutic options for hepatocellular carcinoma with portal vein tumor thrombosis. Liver Cancer 3: 18-30, 2014.

9. Im JH, Yoon SM, Park HC, Kim JH, Yu JI, Kim TH, Kim JW, Nam TK, Kim K, Jang HS, et al: Radiotherapeutic strategies for hepatocellular carcinoma with portal vein tumour thrombosis in a hepatitis B endemic area. Liver Int 37: 90-100, 2017.

10. Phillips WT, Bao A, Brenner AJ and Goins BA: Image-guided interventional therapy for cancer with radiotherapeutic nanoparticles. Adv Drug Deliv Rev 76: 39-59, 2014.

11. Freed-Pastor W and Prives C: Targeting mutant p53 through the mevalonate pathway. Nat Cell Biol 18: 1122-1124, 2016.

12. Muller PA and Vousden KH: p53 mutations in cancer. Nat Cell Biol 15: 2-8, 2013.

13. Muller PA and Vousden KH: Mutant p53 in cancer: New functions and therapeutic opportunities. Cancer Cell 25: 304-317, 2014.

14. Lencioni R and Llovet JM: Modified RECIST (mRECIST) assessment for hepatocellular carcinoma. Semin Liver Dis 1: 52-60, 2010.

15. Xia J, Ren Z, Ye S, Sharma D, Lin Z, Gan Y, Chen Y, Ge N, Ma Z, Wu Z, et al: Study of severe and rare complications of transarterial chemoembolization (TACE) for liver cancer. Eur J Radiol 59: 407-412, 2006.

16. Jihye $C$ and Jinsil S: Application of radiotherapeutic strategies in the BCLC-defined stages of hepatocellular carcinoma. Liver Cancer 1: 216-225, 2012.

17. Herfarth KK, Debus J, Lohr F, Bahner ML, Rhein B, Fritz P, Höss A, Schlegel W and Wannenmacher MF: Stereotactic singledose radiation therapy of liver tumors: Results of a phase I/II trial. J Clin Oncol 19: 164-170, 2001.

18. Salem R, Thurston KG, Carr BI, Goin JE and Geschwind JF: Yttrium-90 microspheres: Radiation therapy for unresectable liver cancer. J Vasc Interv Radiol 13: S223-S229, 2002.

19. Matsuura M, Nakajima N, Arai K and Ito K: The usefulness of radiation therapy for hepatocellular carcinoma. Hepatogastroenterology 45: 791-796, 1998. 
20. Seong J, Keum KC, Han KH, Lee DY, Lee JT, Chon CY, Moon YM, Suh CO and Kim GE: Combined transcatheter arterial chemoembolization and local radiotherapy of unresectable hepatocellular carcinoma. Int J Radiat Oncol Biol Phys 43: 393-397, 1999.

21. Jung WS and Shin RM: The effect of patient position on dose in radiation therapy of liver cancer. J Korean Soc Radiotherapeutic Technol 1: 1-9, 2014.

22. Roake CM and Artandi SE: Control of cellular aging, tissue function, and cancer by p53 downstream of telomeres. Cold Spring Harb Perspect Med 7: 26088, 2017.

23. Smet FD, Rubio M and Hompes S: Nuclear inclusion bodies of mutant and wild-type p53 in cancer: A hallmark of p53 inactivation and proteostasis remodeling by p53 aggregation. J Pathol 2: 875-882, 2016.
24. Rahman M, Lovat F, Romano G, Calore F, Acunzo M, Bell EH and Nana-Sinkam P: miR-15b/16-2 regulates factors that promote p53 phosphorylation and augments the DNA damage response following radiation in the lung. J Biol Chem 289: 26406-26416, 2014.

25. Rubner Y, Muth C, Strnad A, Derer A, Sieber R, Buslei R, Frey B, Fietkau R and Gaipl US: Fractionated radiotherapy is the main stimulus for the induction of cell death and of Hsp70 release of p53 mutated glioblastoma cell lines. Radiat Oncol 9: 89, 2014.

(i) (9) This work is licensed under a Creative Commons Attribution-NonCommercial-NoDerivatives 4.0 International (CC BY-NC-ND 4.0) License. 